\title{
The Arbitrariness of Age Ceilings in Developmental Services
}

\author{
Stephen Greenspan* \\ Emeritus Professor of Educational Psychology, University of Connecticut, USA
}

Submission: December 10, 2018; Published: December 19, 2018

*Corresponding author: Stephen Greenspan, Emeritus Professor of Educational Psychology, University of Connecticut, Connecticut, USA

\section{Mini Review}

When determining eligibility for disability-related services, supports and protections, bureaucracies (schools, courts, adult service agencies, etc.) have a strong preference for clear-cut decision and eligibility rules [1]. An example of this would be IQ cut-offs (e.g., 70) for determining whether someone qualifies as having an Intellectual Disability (ID). The reason for this preference is obvious: bureaucrats and other decision-makers typically lack the time or training to deal with the complexity of individual situations.

However, there are two problems with the use of rigid disability eligibility rules, such as IQ cut-offs:

i. There are cases when a cut-off (such as an IQ ceiling of 70) will create a "false negative" decision, i.e., a deserving individual will be wrongly denied services, and

ii. As views of ID change over time, the cut-offs will need to be adjusted (typically by loosening them somewhat) to make for fairer decisions.

With respect to the first problem (wrongly denying services), a common solution to the over-emphasis on full-scale IQ scores has been to implement "ID equivalence" provisions, such as the use of the broader concept of "developmental disabilities" [2]. With respect to the second problem (changing of eligibility criteria over time), this has most dramatically been illustrated in the shift from an overly inclusive IQ cut-off of 85 (AAIDD, from 1961 to 1972), to an overly exclusive IQ cut-off of 70 (AAIDD 1973 to 1992), to a slightly more inclusive IQ cut-off of 75 (DSM-5, and AAIDD 1992 to its most recent 2010 manual), with further flexibility granted by the recommendation to consider two sources of unreliability:

i. Standard error of test scores, and

ii. The so-called "Flynn effect" (shift in IQ norms to account for population intelligence changes by subtracting three fullscale points for each decade of test obsolescence).

As almost all readers of this Journal know, the definition of ID for the past half-century has had three so-called "prongs":

i. Impairments in intellectual functioning (as measured by IQ and other cognitive tasks), ii. Deficits in "adaptive functioning" or "adaptive behavior" (need for supports in everyday life, as measured by either third-party rating instruments or documentary evidence) and

iii. Onset of the first two prongs within what is termed the "developmental period" [3].

This third criterion, while generally less of an obstacle to fair decision-making than the first two, has also been affected by the same two issues of unfair denial of services and shift in definition (in order to correct for such unfairness) over time.

An example of the first phenomenon would be when an individual suffers a catastrophic medical event such as a traumatic brain injury just a short while after the arbitrary developmental ceiling takes effect, and as a consequence is denied services or protections, even when his or her needs are identical to (and sometimes even greater) than those of someone who meets the arbitrary age ceiling. An example of the second phenomenon can be seen in the fact that AAIDD (back when it was known as AAMD and later as AAMR) initially set the third prong as onset before age 16 , then shifted it to age 18 , and there are some criminal court jurisdictions (such as Utah and a couple of other American states) and some civil bureaucratic jurisdictions (most prominently the United States developmental disability laws) which set the developmental onset criterion as prior to age 22 .

Although the two major ID diagnostic manuals (AAIDD and DSM) are in general agreement on most matters, there is a divergence with regard to the developmental onset criterion, in that in 2013 the American Psychiatric Association (the publisher of the DSM-5 manual) kept the emphasis on onset within the developmental period but did not provide any specific definition of that period in terms of an age cut-off. The reason for this change is that psychiatry is a medical discipline, and in medicine there is a greater appreciation of brain science and also of the need to afford diagnosing clinicians freedom to exercise clinical judgment regarding the circumstances of each diagnosed individual. This change also reflects an understanding that the arbitrary use of the age 18 cut-off fails to reflect the fact that neuroscientists are in general agreement that the brain continues to develop into one's twenties [4]. 
Although AAIDD, being an organization dominated by serviceproviding bureaucrats, is less likely than the more medicallyoriented DSM to do away with a specific age cut-off specification, there is a strong likelihood, approaching near certainty, that the age 18 ceiling will be dramatically loosened in its next classification manual. While the manual-revising committee of AAIDD is operating under a veil of secrecy, there are strong indications that it will raise the developmental ceiling in the next manual, scheduled for release in late 2020 or early 2021. For example, consensus among the organization's membership has shifted, as reflected in the fact that at the Spring 2018 AAIDD convention, the matter was put to a straw vote of attendees and the show of hands was overwhelmingly in favor of change. Furthermore, this author has it on good authority from someone close to the committee [5] that the next manual will loosen prong three, almost certainly by raising the ceiling from age 18 to age 22 .

A disability is a functional entity, in that its boundaries are established not by underlying organic factors (unlike a contributing disorder such as Fetal Alcohol Syndrome, which is a medical category) but by measurable outward signs and indicators. As such, a disability is defined by an authoring committee and the opinions of such a committee evolves as new

evidence accumulates. Whether operating within a bureaucratic (AAIDD) or more medical (DSM) framework, there is now consensus within the ID field that just as a prong one cut-off of 70 was too restrictive, the same can be said for maintenance of the outmoded third prong notion that ID must always be manifested before age 18.

\section{References}

1. Harris JC, Greenspan S (2016) Nature and definition of intellectual and developmental disabilities. In NN Singh (edn), Clinical handbook of evidence-based practices for individuals with IDD (p.11-39) Springer: New York, USA.

2. Greenspan S, Woods GW, Switzky HN (2015). Age of onset and the developmental period criterion. In: E Polloway (edn), Death penalty and intellectual disability, AAIDD.

3. Greenspan S, Brown NN, Edwards W (2015) FASD and the concept of "Intellectual Disability Equivalence." In: M Nelson \& M. Trussler (edn.), Law and Ethics in Fetal Alcohol Spectrum Disorder. Springer: Amsterdam, Europe.

4. Scott E, Duell N, Steinberg L (2018) Brain development, social context and justice policy. Washington University Journal of Law and Policy 57: 13-74.

5. Anonymous (2019) Personal communication.

\section{Your next submission with Juniper Publishers will reach you the below assets}

- Quality Editorial service

- Swift Peer Review

- Reprints availability

- E-prints Service

- Manuscript Podcast for convenient understanding

- Global attainment for your research

- Manuscript accessibility in different formats

( Pdf, E-pub, Full Text, Audio)

- Unceasing customer service

Track the below URL for one-step submission

https://juniperpublishers.com/online-submission.php 